\title{
Gestão do risco de crédito de cooperativas: um estudo comparativo
}

\author{
Credit risk management of cooperatives: a comparative study
}

\author{
M. Picinini Méxas ${ }^{1 *}$; L. P. Jacques Silva ${ }^{2}$, G. Meirelles Drumond ${ }^{3}$ \\ ${ }^{I}$ Departamento de Ciências Contábeis, Universidade Federal Fluminense,CEP 24020-140,Niterói-RJ, Brasil \\ ${ }^{2}$ Departamento de Ciências Contábeis, Universidade Federal Fluminense, CEP 24020-140,Niterói-RJ, Brasil \\ ${ }^{3}$ Superintendência de Documentação, Universidade Federal Fluminense, CEP 24210-201, Niterói, RJ, Brasil
}

*mirian.picinini@gmail.com

(Recebido em 05 de junho de 2016; aceito em 06 de novembro de 2016)

\begin{abstract}
A crise econômica que está ocorrendo no Brasil a partir de 2015 tem levado ao corte dos acessos de linha de crédito. Diante desta problemática, o presente trabalho analisou qual tipo de cooperativa de crédito apresenta uma melhor gestão do risco de crédito, resultado de baixos índices de inadimplência relacionados à carteira de crédito composta por operações negociadas junto aos cooperados. Além da revisão da literatura, a metodologia utilizada foi uma pesquisa descritiva ao analisar e interpretar os dados contidos nos relatórios de gestão do risco de crédito extraídos do sistema de informações interno, para os anos de 2013, 2014 e 2015, referentes a três cooperativas de crédito com área de atuação no estado do Rio de Janeiro, sendo cada uma classificada nos seguintes tipos: livre admissão, profissionais e microempresários. $\mathrm{O}$ resultado da pesquisa indica que a cooperativa de crédito de livre admissão obteve, como resultado de sua gestão do risco de crédito, os menores índices de inadimplência para operações com atraso superiores a 15 e 90 dias nos três anos que delimitam a pesquisa. Como contribuição o estudo identificou qual o tipo de cooperativa é mais estruturada e segura para ser a escolhida pelo potencial cooperado para que ele se associe e invista.
\end{abstract}

Palavras-chave: Cooperativa de crédito, Risco de crédito, Inadimplência.

The economic crisis that is taking place in Brazil since 2015 has led to cut the credit line access. Faced with this problem, this study analyzed which type of credit union offers a better credit risk management, a result of low default rates related to the credit portfolio composed of transactions with the cooperative members. In addition to the literature review, the methodology used was a descriptive research to analyze and interpret the data in the credit risk management reports extracted from internal information system for the years 2013, 2014 and 2015, relating to three credit unions with operating area in the state of Rio de Janeiro, each one is classified into the following types: free admission, professionals and micro entrepreneurs. The research result indicates that the credit union of free admission obtained as a result of its management of credit risk, the lowest rates of default for operations with a delay of more than 15 and 90 days in the three years, that delimits the search. As a contribution, the study identified what type of cooperative is more structured and safe to be chosen by the potential co-operated so that it associates and invest.

Keywords: Credit union, Credit risk, Default.

\section{INTRODUÇÃO}

O setor do cooperativismo é de impreterível importância para os sistemas financeiros, uma vez que incentiva o investimento dos recursos privados dos cooperados, e assume os riscos em virtude da própria sociedade onde a cooperativa está inserida, consequentemente, onde se desenvolve. Por se valerem a partir de iniciativas espontâneas dos cooperados que a fundam, uma cooperativa contribui significativamente para o desenvolvimento sustentável da comunidade em que está inserida, principalmente quando da criação de carteiras de poupança e de financiamento de projetos empresariais, sendo assim, beneficiam de maneira importante estes locais, na medida em que geram empregos e ampliam a distribuição de renda [1]. 
As cooperativas de crédito têm desempenhado papel fundamental pela inclusão financeira de milhares de pessoas em todo país em função da sua característica solidária, em que oferecem aos seus associados, a possibilidade de obterem crédito com taxas diferenciadas e com maior flexibilização da forma de pagamento [2]. Embora existam barreiras naturais que impedem o crescimento do cooperativismo, ele tem se mostrado uma alternativa viável para atenuar os problemas socioeconômicos [3].

Segundo Vilares [4]

O cooperativismo vem crescendo num ritmo mais forte em todos os indicadores quando comparado ao conjunto do Sistema Financeiro Nacional (SFN). As cooperativas já ocupam a $6^{a}$ posição no ranking das maiores instituições financeiras do Brasil (considerando ativos, depósitos, patrimônio líquido e operações de crédito) e já possui a maior rede de atendimento do país. A perspectiva é de que o segmento influencie ainda mais as economias regionais nos próximos anos devido à estabilidade financeira e juros mais atrativos para os associados.

Com seu início e desenvolvimento na Europa no século 18, as cooperativas de crédito nos países que já o utilizam há muito tempo, como especialmente na Alemanha, na Bélgica, na Espanha, na França, na Holanda e em Portugal, funcionam como instrumento impulsionador de setores econômicos estratégicos. Em alguns países, como Irlanda e Canadá, o cooperativismo de crédito ocupa, com bastante eficiência, espaços deixados pelas instituições bancárias, como resposta ao fenômeno mundial da concentração, reflexo da forte concorrência no setor financeiro. As cooperativas estão conseguindo manter os empregos nas pequenas comunidades e ofertar serviços mais adequados às necessidades locais [5]

No Brasil, deu-se início ao cooperativismo de crédito no ano de 1902 e teve como precursor do cooperativismo de crédito o Padre Teodoro Armstad, que juntamente com 19 colonos, em Nova Petrópolis - RS, fundou a primeira cooperativa de crédito no Brasil - Sociedade Cooperativa Caixa Economia e Empréstimos de Nova Petrópolis -, hoje denominada Sicredipioneira. Essa cooperativa, tem como particularidade, o fato de ter contado com apenas 4 presidentes em 100 anos de existência [6].

Baseado na Lei da Reforma Bancária, de $\mathrm{n}^{\circ}$ 4.595, datada de 31 de dezembro de 1964, definiuse que o critério de funcionamento, a regulação e a fiscalização das cooperativas de crédito estariam sob a responsabilidade do Banco Central do Brasil, o qual consiste em um fundamental órgão de apoio governamental ao cooperativismo de crédito [7].

O desenvolvimento de projetos e relatórios que tem como objetivo estimular o cooperativismo por esta autarquia associa-se a ideia de que, somente quando cidadãos pouco favorecidos e micro e pequenos empresários obtêm acesso aos serviços e créditos financeiros, viabiliza-se o desenvolvimento de um país.

As cooperativas de crédito são instituições financeiras estruturadas nos moldes de sociedade cooperativa, tendo por finalidade fornecer serviços financeiros aos cooperados, tais como concessão de crédito, serviços de cobrança, captação de depósitos à vista e a prazo, cheques, carteira de poupança, serviços de custódia, além de outras operações específicas e atribuições estabelecidas na legislação em vigor [8].

Ao longo dos anos, as cooperativas de crédito se tornaram um importante elemento do Sistema Financeiro Nacional, sofrendo alterações, principalmente nos moldes legislativos, em consonância com o desenvolvimento econômico e político do país, embora tenham crescido, desde a Lei Cooperativista (5.764/1971), mesmo em cenários de crises econômicas e políticas no país, se diferenciando do retrospecto no mesmo período, das instituições financeiras [9].

Hoje, o modelo atual consiste nas prerrogativas traçadas na Resolução $\mathrm{n}^{\circ} 4.434$, de 2015, normatizada pelo Conselho Monetário Nacional, e publicada pelo Banco Central do Brasil, que estabelece uma nova etapa para o sistema de cooperativas de crédito, a qual se iniciou em 2003, com a regulamentação das cooperativas de crédito de livre admissão [10].

A respeito do quantitativo de instituições, tendo por base o tipo de vínculo associativo, o crescimento no número de cooperativas de livre admissão destacou-se em relação ao panorama 
geral nos últimos quatro anos. A participação das cooperativas de livre admissão no quantitativo total passou de 18\% em 2010 para 27\% em 2014 [10].

Quanto aos limites regulamentares, os quais as cooperativas de crédito são obrigadas a seguir como forma de garantir a solidez das cooperativas, bem como, do sistema cooperativo, elas precisam apresentar valores de limite mínimo de Patrimônio Líquido. Conforme o artigo 19 da Resolução 4.434 de 2015, regulamentada pelo Conselho Monetário Nacional, o requerimento mínimo de Patrimônio Líquido exigido pelo Banco Central, a cooperativa de crédito clássica singular filiada a uma cooperativa central deve apresentar, após 5 (cinco) anos de autorização para o funcionamento, o montante de $\mathrm{R} \$ 300.000,00$ [11].

Em observância à Resolução 4.193 de 2013, regulamentada pelo Conselho Monetário Nacional, o limite mínimo do Índice de Basileia analisa a exigência mínima de capital que devem ser respeitados pelas instituições financeiras, frente aos riscos dos ativos, que consiste em $13 \%$ para cooperativas optantes pelo Regime Prudencial Simples [12].

$\mathrm{O}$ Índice de Basileia está relacionado à prerrogativa que as instituições financeiras devem gerenciar os seus riscos, bem como a criação de um colchão de conservação de capital e de um colchão anticíclico de capital e, por conseguinte, a autoridade supervisora exige que as instituições mantenham um montante mínimo de capital próprio que seja proporcional aos riscos de suas operações [13].

Conforme afirmam Pinheiro, Savóia e Securato [13], a exigência de capital nas instituições financeiras surgiu como resposta de risco sistêmico, que se tornou evidente após sucessivas crises financeiras no início dos anos 80 , em que a estabilidade do sistema financeiro dos países credores foi colocada em risco, afetando o equilíbrio da economia mundial.

As cooperativas de crédito são sujeitas aos riscos inerentes à sua atividade, da mesma forma que as demais instituições financeiras. Tais riscos podem ser resumidos nas seguintes categorias: risco de crédito; risco de mercado; liquidez e risco operacional [8].

$\mathrm{O}$ risco de crédito consiste no principal tipo de risco das instituições financeiras, relaciona-se quando as contrapartes não desejam ou não são capazes de cumprir suas obrigações contratuais, e ainda, seu efeito se mede pelo custo de reposição de fluxos de caixa, caso a parte fique inadimplente. Para tanto é necessário à adoção e padronização dos critérios de análise e aceitação de risco, em que tal estratégia permite decisões com maior grau de acerto decorrente de uma análise mais ampla e de um maior comprometimento com os resultados [14].

Conforme afirma Securato [15], o responsável pela decisão da concessão do crédito sempre enfrenta o desconforto de saber que entre o sim e o não pode estar evitando um insucesso ou perdendo uma grande oportunidade de negócio. Por esses motivos, o risco de crédito sempre foi alvo de atenção das instituições financeiras. A probabilidade baseada em dados históricos de se estimar diferentes resultados é a definição de risco, cabendo ao tomador de decisões, estando baseada em uma sensibilidade pessoal. A relevância do gerenciamento de risco de crédito tem crescido ultimamente, devido a fatores como: crescimento estrutural nas falências, margens de empréstimos mais competitivas, queda no valor dos ativos reais em grande parte do mundo, implicando queda no valor das garantias das operações de crédito.

Atualmente, evidencia-se, no Brasil, a forte restrição à concessão de crédito e isto tem travado os negócios das empresas e das pessoas em vários setores da economia, além do aumento das taxas de juros.

Conforme afirma Fernandes [16], no momento em que se concede crédito, a maior das preocupações é a possibilidade de que o cooperado não honre seus compromissos assumidos. As cooperativas de crédito se deparam com a inadimplência, a qual ocasiona perdas de rentabilidade e, dependendo do nível de reincidência, pode descontinuar uma instituição financeira. Para tanto, a inadimplência é a principal incógnita que preocupa qualquer instituição que fornece crédito. Afinal, a aprovação da operação de crédito e a dimensão das taxas de juros cobradas, são influenciadas pelos riscos que envolvem a carteira de operações de crédito.

No caso específico das cooperativas de crédito, conforme afirma Tavares [8], o risco de inadimplência é a quantificação numérica da incerteza quanto à devolução futura de um valor emprestado, a ser pago pelo tomador do crédito para a instituição, desprezando as expectativas de realização de garantias. 
Segundo Saunders [17, p. 177], os riscos de crédito e a inadimplência, para as instituições financeiras, podem resultar no seguinte:

\begin{abstract}
Os problemas de qualidade de crédito, no pior dos casos, podem resultar na insolvência da instituição financeira. Ou podem resultar, tanto em um significante dreno sobre o capital e patrimônio líquido, como afetar adversamente as perspectivas de crescimento da instituição e sua habilidade de competir com outras instituições domésticas ou internacionais.
\end{abstract}

Nessa nova conjuntura, somente as cooperativas de crédito que gerenciem o risco de crédito de modo eficaz e estratégico conseguem antever o comportamento de sua carteira de operações de crédito diante das alterações do cenário macroeconômico, precificando suas operações com maior exatidão, evadindo-se de quaisquer exposições ao risco desnecessárias se qualificando, ainda, a competir no mercado financeiro.

Este cenário de corte aos acessos de linha de crédito diminui o capital de giro e investimentos das empresas, além de causar uma restrição maior de compra por parte do consumidor.

Em vista da problemática apresentada, buscou-se analisar o risco de crédito para as cooperativas com o intuito de entender qual tipo de cooperativa é mais afetada em função do cenário econômico atual, e se estas instituições financeiras continuam em processo de expansão, obtendo resultados positivos e preservando a inadimplência em níveis aceitáveis, mesmo em um cenário pouco favorável à oferta creditícia.

Sendo assim, o objetivo da pesquisa é demonstrar qual tipo de cooperativa de crédito é menos exposta aos riscos de crédito no Sistema Financeiro Nacional, evidenciando-se o melhor tipo entre as cooperativas de crédito para se associar e investir.

\title{
2. MATERIAL E MÉTODOS
}

A pesquisa se classifica como bibliográfica, exploratória e descritiva [18], tendo em vista que visa analisar e se aprofundar na relação entre a exposição do risco de crédito e o ramo ao qual a cooperativa de crédito está inserida, se familiarizando com os conceitos sobre o cooperativismo de crédito, os riscos inerentes as suas atividades e a gestão do risco de crédito, além de analisar e descrever sobre os dados coletados, buscando avaliar os tipos de cooperativa de crédito que possuem uma maior gestão do risco de crédito, evidenciando quais sustentam sua perpetuidade no sistema financeiro nacional.

A pesquisa bibliográfica relaciona-se com a contextualização do tema, sendo realizada através das seguintes fontes bibliográficas: livros, artigos de periódicos e dissertações. A pesquisa documental foi realizada em relatórios privados e públicos referentes às operações de crédito e níveis de inadimplência.

Quanto aos relatórios de gestão de risco de crédito, sendo estes, dados de fonte primária, foram extraídos do sistema de informação tecnológica integrado do sistema cooperativo em que as três cooperativas desta pesquisa fazem parte. Todas as três pertencem a um sistema cooperativo de nível nacional, composto por uma Confederação, um Banco, e diversas Centrais, sendo que, dentre estas, as cooperativas escolhidas para a pesquisa são filiadas a Central que atua no estado do Rio de Janeiro.

Essas cooperativas apresentam a seguinte tipologia: livre admissão, composta por grupos de associados de diversas origens e atividades econômicas (Cooperativa A); de profissionais, formada por pessoas de uma determinada profissão ou atividade (Cooperativa B); e de microempresários (Cooperativa C) [19]. Os relatórios utilizados fornecem as informações referentes às datas base dezembro de 2013, 2014 e 2015, representando assim, os resultados de cada exercício.

Foram evidenciados inicialmente, por meio de análise aos relatórios, os perfis de gestão de risco de crédito das cooperativas de crédito $\mathrm{A}, \mathrm{B}$ e $\mathrm{C}$, considerando os seus níveis de 
inadimplência no período de 2013 a 2015, e sucessivamente realizado um comparativo que possibilite o alcance dos objetivos da pesquisa.

\section{RESULTADOS E DISCUSSÃO}

Inicialmente foi apresentado a seguir o perfil sobre cada uma das três cooperativas de crédito A, B e C, e depois foi realizada uma análise comparativa entre elas.

\subsection{PERFIL DA COOPERATIVA DE CRÉDITO DE LIVRE ADMISSÃO}

Para as análises do gerenciamento do risco de crédito, primeiro foi escolhida uma cooperativa de livre admissão filiada a uma Central, aludida nas análises como Cooperativa $\mathrm{A}$, com sede e atuação no estado do Rio de Janeiro e pertencente a um sistema cooperativo nacional. Os dados sobre a inadimplência no período de 2013 a 2015 estão apresentados na Tabela 1 a seguir e também ilustrados na Figura 1.

A Tabela 1 apresenta os percentuais de inadimplência de operações com atraso acima de 15 e 90 dias, para a Cooperativa A, evidenciando-se ainda, a quantidade de contratos e o montante do saldo da carteira de operações de crédito.

Tabela 1: Inadimplência de operações com atraso acima de 15 e 90 dias para a Cooperativa A

\begin{tabular}{ccccc}
$\begin{array}{c}\text { Anos da } \\
\text { Cooperativa A }\end{array}$ & $\begin{array}{c}\text { Quantidade de } \\
\text { Contratos }\end{array}$ & Saldo & $\begin{array}{c}\text { INAD } \\
\mathbf{1 5}\end{array}$ & $\begin{array}{c}\text { INAD } \\
\mathbf{1 0}\end{array}$ \\
\hline 2013 & 2.909 & $17.668 .487,34$ & $0,42 \%$ & $0,23 \%$ \\
2014 & 3.566 & $22.605 .452,41$ & $1,11 \%$ & $57,00 \%$ \\
2015 & 8.171 & $32.831 .190,95$ & $3,55 \%$ & $2,16 \%$ \\
\hline
\end{tabular}

Conforme apresentado na Figura 1, observa-se a expansão dos níveis de inadimplência da Cooperativa A, no decorrer dos exercícios de 2013, 2014 e 2015, que foi impactado, principalmente, pelo atual cenário econômico em que o país está transitando, porém, o objetivo desta pesquisa é evidenciar os resultados no risco de crédito das diferentes gestões pelas cooperativas, visto que todas estão inseridas no mesmo sistema financeiro. Nota-se que houve um maior crescimento na inadimplência 


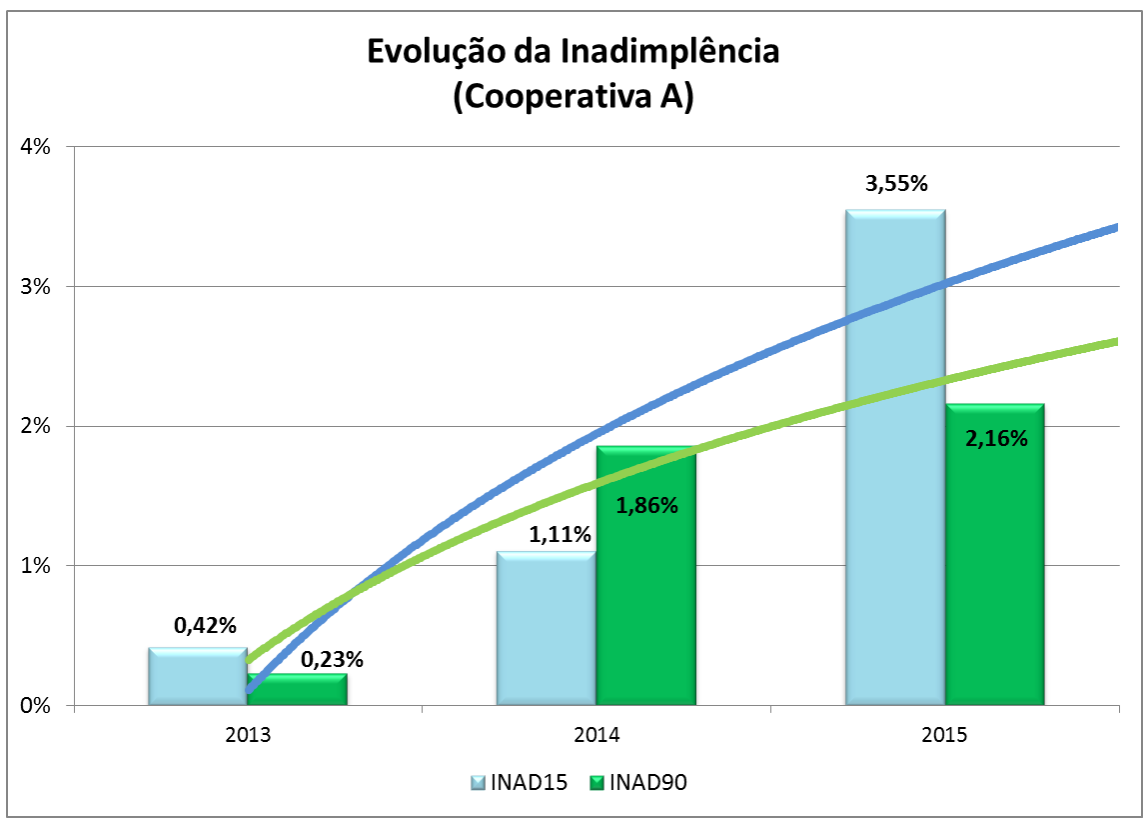

Figura 1: Evolução da Inadimplência (Cooperativa A)

\subsection{PERFIL DA COOPERATIVA DE CRÉDITO DE PROFISSIONAIS}

A segunda cooperativa escolhida para as análises do gerenciamento do risco de crédito foi uma cooperativa de profissionais filiada a uma Central, aludida nas análises como Cooperativa B, com sede e atuação no estado do Rio de Janeiro e pertencente a um sistema cooperativo nacional. Os dados sobre a inadimplência no período de 2013 a 2015 estão apresentados na Tabela 2 a seguir e também ilustrados na Figura 2.

A Tabela 2 apresenta os percentuais de inadimplência de operações com atraso acima de 15 e 90 dias, para a Cooperativa B, evidenciando-se ainda, a quantidade de contratos e o montante do saldo da carteira de operações de crédito.

Tabela 2: Inadimplência de operações com atraso acima de 15 e 90 dias para a Cooperativa $B$

\begin{tabular}{ccccc}
$\begin{array}{c}\text { Anos da } \\
\text { Cooperativa B }\end{array}$ & $\begin{array}{c}\text { Quantidade de } \\
\text { Contratos }\end{array}$ & Saldo & $\begin{array}{c}\text { INAD } \\
\mathbf{1 5}\end{array}$ & $\begin{array}{c}\text { INAD } \\
\mathbf{1 0}\end{array}$ \\
\hline 2013 & 2.865 & $10.840 .087,23$ & $3,96 \%$ & $1,40 \%$ \\
2014 & 3.200 & $10.205 .126,22$ & $3,95 \%$ & $1,50 \%$ \\
2015 & 3.905 & $9.382 .557,38$ & $9,74 \%$ & $4,47 \%$ \\
\hline
\end{tabular}

Tendo em vista os dados apresentados na Figura 2, observa-se a dilatação repentina dos níveis de inadimplência da Cooperativa B, na transição do exercício de 2014 para 2015, que foi resultado, principalmente, do impacto da recessão econômica na administração financeira da empresa em que os cooperados são empregados, caracterizando-se, especificamente, a cooperativa de empregados de determinada empresa. 


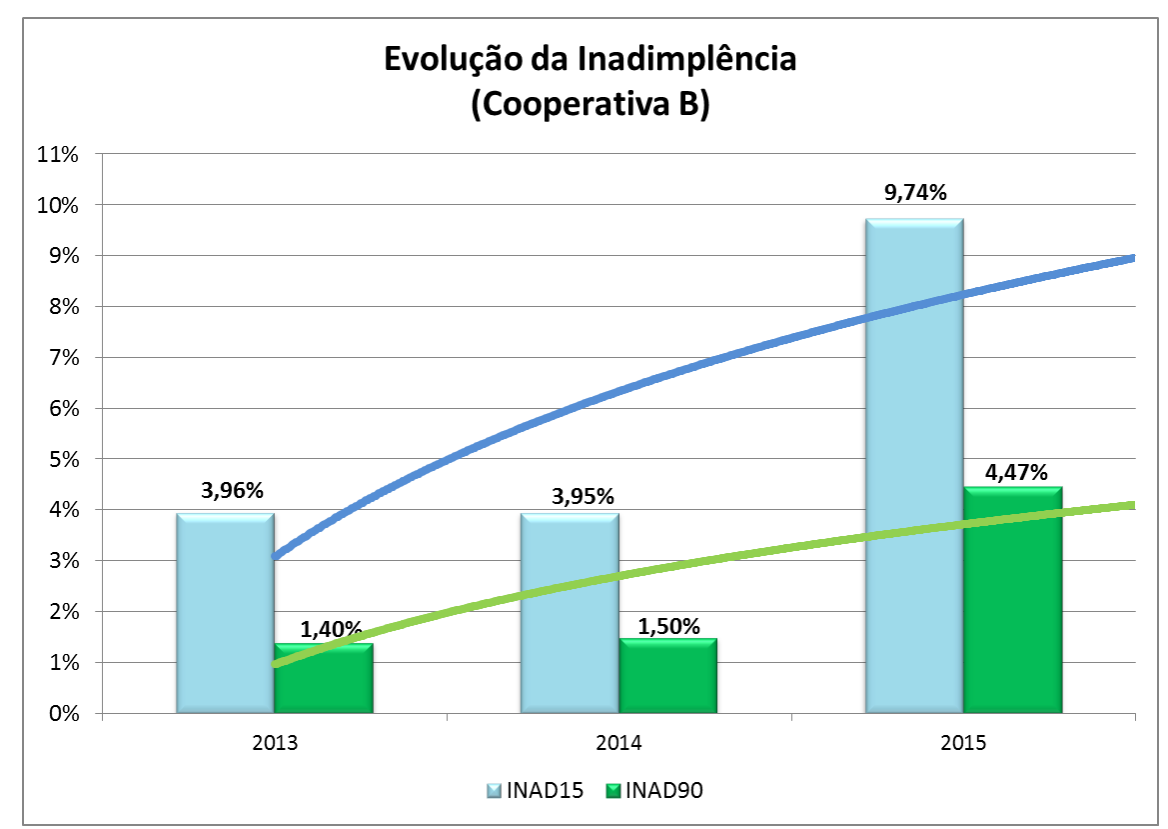

Figura 2: Evolução da Inadimplência (Cooperativa B)

\subsection{PERFIL DA COOPERATIVA DE CRÉDITO DE MICROEMPRESÁRIOS}

Por último, a terceira cooperativa escolhida para as análises do gerenciamento do risco de crédito foi uma cooperativa de microempresários filiada a uma Central, aludida nas análises como Cooperativa C, com sede e atuação no estado do Rio de Janeiro e pertencente a um sistema cooperativo nacional. Os dados sobre a inadimplência no período de 2013 a 2015 estão apresentados na Tabela 3 a seguir e também ilustrados na Figura 3.

A Tabela 3 apresenta os percentuais de inadimplência de operações com atraso acima de 15 e 90 dias, para a Cooperativa C, evidenciando-se ainda, a quantidade de contratos e o montante do saldo da carteira de operações de crédito.

Tabela 3: Inadimplência de operações com atraso acima de 15 e 90 dias para a Cooperativa C

\begin{tabular}{ccccc}
$\begin{array}{c}\text { Anos da } \\
\text { Cooperativa C }\end{array}$ & $\begin{array}{c}\text { Quantidade } \\
\text { de Contratos }\end{array}$ & Saldo & $\begin{array}{c}\text { INAD } \\
\mathbf{1 5}\end{array}$ & $\begin{array}{c}\text { INAD } \\
\mathbf{1 0}\end{array}$ \\
\hline 2013 & 1.671 & $12.304 .607,09$ & $7,73 \%$ & $3,82 \%$ \\
2014 & 1.937 & $15.459 .908,81$ & $4,87 \%$ & $1,06 \%$ \\
2015 & 3.147 & $19.633 .160,02$ & $4,23 \%$ & $3,47 \%$ \\
\hline
\end{tabular}

Conforme a Figura 3, em análise à evolução da inadimplência da Cooperativa $\mathrm{C}$, observa-se a queda expressiva no decorrer dos exercícios de 2013, 2014 e 2015, o que indica que a cooperativa administra de maneira aceitável a gestão ao risco, ainda que vivencie a mesma recessão econômica que suas coirmãs. 


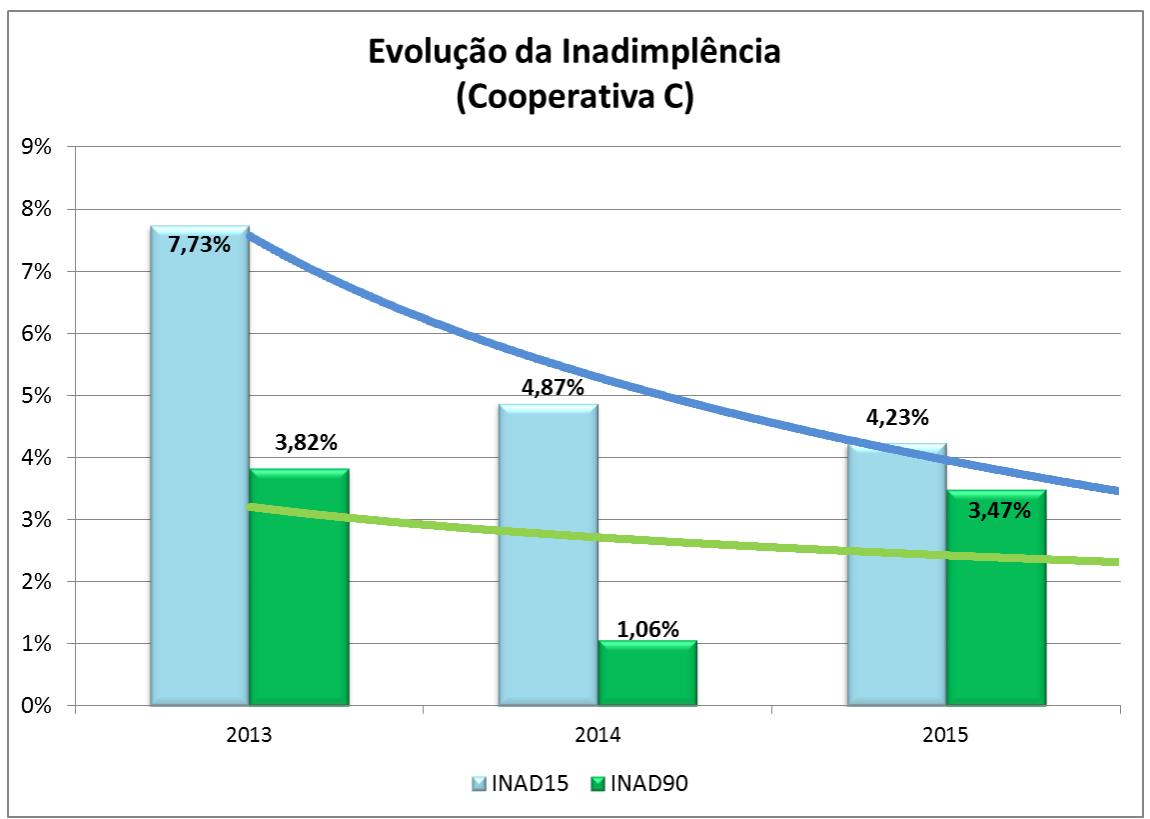

Figura 3: Evolução da Inadimplência (Cooperativa C)

\subsection{COMPARATIVO ENTRE OS RESULTADOS DA GESTÃO DO RISCO DE CRÉDITO DAS COOPERATIVAS}

Realizou-se o comparativo entre os resultados obtidos através dos dados observados nos relatórios gerenciais de risco de crédito das três cooperativas. Por meio deste comparativo buscase avaliar a qualidade da gestão do risco de crédito, comparando as cooperativas entre si, e identificando a melhor manutenção dos níveis de inadimplência.

Em análise ao exercício de 2013, conforme Figura 4, foi estruturado o comparativo entre os percentuais de inadimplência de operações com atraso acima de 15 e 90 dias, para as Cooperativas A, B e C.

Nota-se, na Figura 4, que no ano de 2013, a Cooperativa A obteve os melhores índices de inadimplência para operações com atraso superior a 15 e 90 dias, ou seja, alcançou percentuais mais baixos em relação às Cooperativas $\mathrm{B}$ e $\mathrm{C}$. 


\section{Índices de inadimplência em 2013}

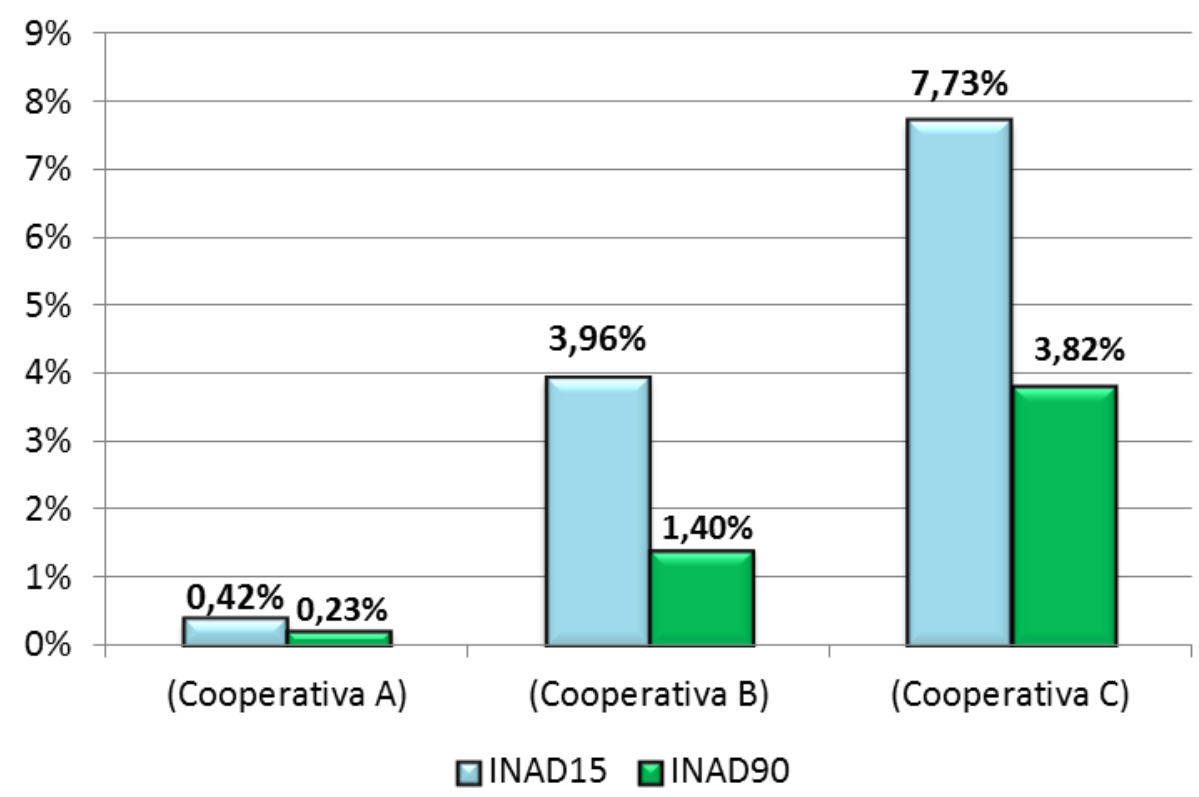

Figura 4: Comparativo da inadimplência de 15 e 90 dias em 2013

Cabe observar ainda, a Figura 5, que evidencia o conjunto das carteiras de crédito das três cooperativas e suas respectivas representatividades no ano de 2013.

\section{Carteiras de Crédito \\ Exercício de 2013}

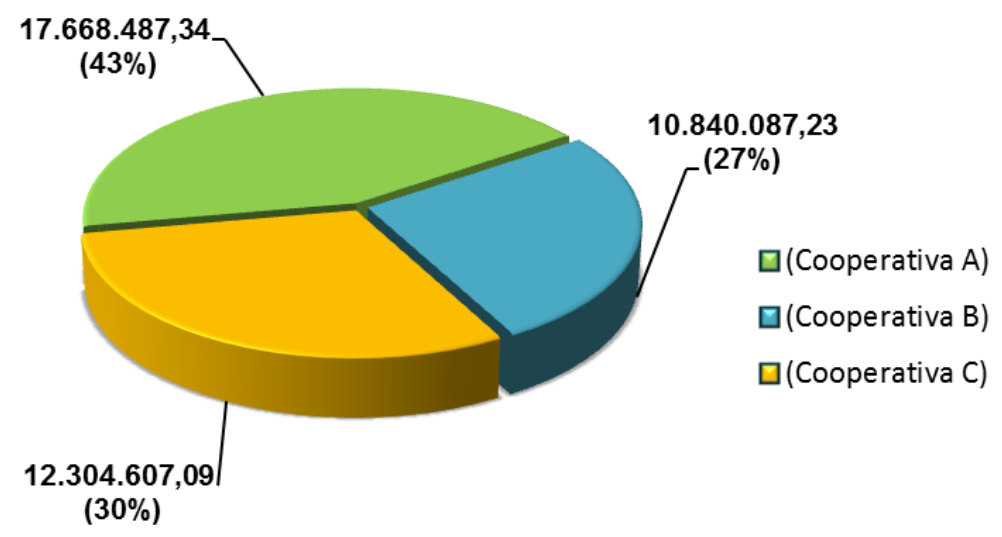

Figura 5: Carteiras de créditos das três cooperativas em 2013 (dados obtidos dos saldos das tabelas 1, 2, e3)

Partindo-se do pressuposto que a cooperativa de livre admissão (Cooperativa A) opera com um público mais amplo e possui a maior carteira de crédito dentre as demais cooperativas da pesquisa, conforme a Figura 5, esse resultado demonstra que esta Cooperativa possuía uma ótima gestão de risco de crédito, quando sua inadimplência para operações com atraso superior a 15 e 90 dias alcançavam, respectivamente, $0,42 \%$ e $0,23 \%$ da carteira de operações de crédito. 
Alternando a análise ao exercício de 2014, foi estruturado, também, na Figura 6, o comparativo entre os percentuais de inadimplência de operações com atraso acima de 15 e 90 dias, para as Cooperativas A, B e C.

Ao analisar a Figura 6, observa-se que no ano de 2014 a Cooperativa A alcançou, novamente, os melhores índices de inadimplência para operações com atraso superior a 15 e 90 dias em relação às Cooperativas $\mathrm{B}$ e C.

\section{Índice de inadimplência em 2014}

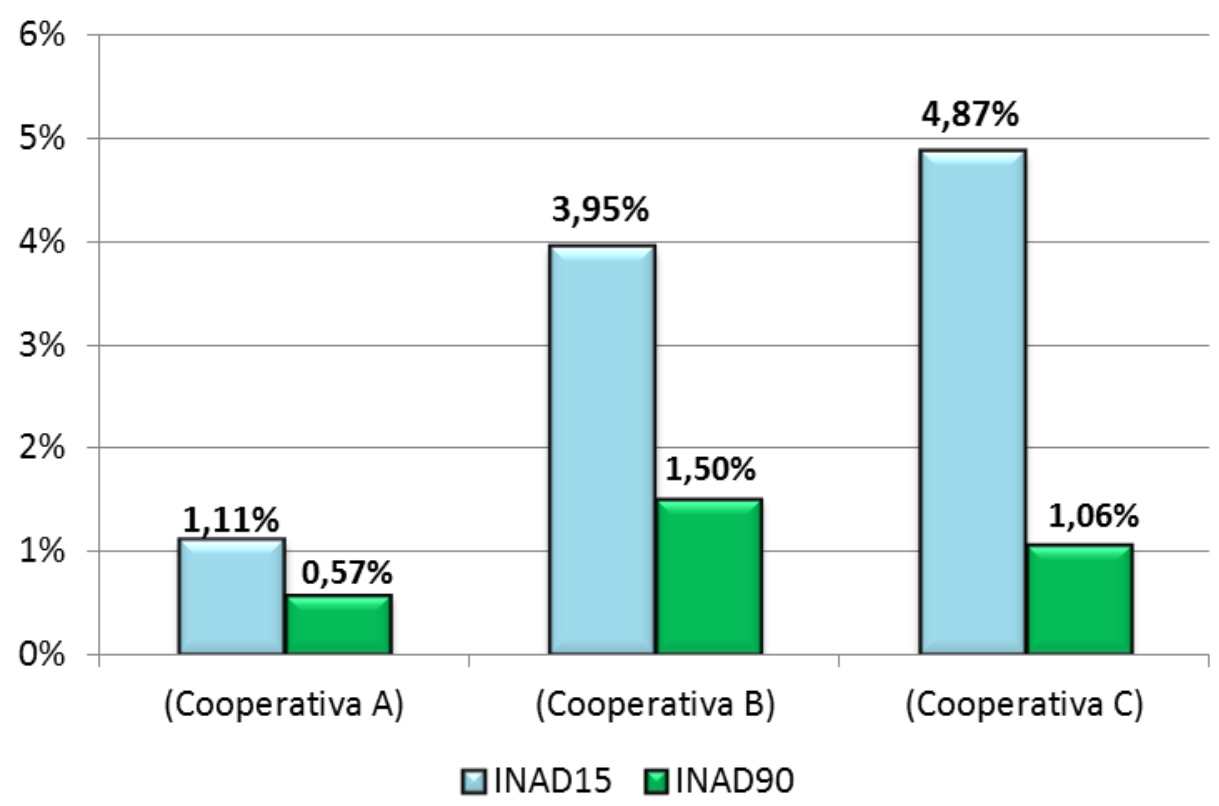

Figura 6: Comparativo da inadimplência de 15 e 90 dias em 2014

Observa-se ainda, a Figura 7, que evidencia o conjunto das carteiras de crédito das três cooperativas e suas respectivas representatividades no ano de 2014. A Cooperativa A continua operando com um público mais amplo que as demais cooperativas, sendo que ocorreu uma pequena diminuição no saldo da Cooperativa $\mathrm{C}$, enquanto o saldo das outras continua crescendo.

\section{Carteiras de Crédito \\ Exercício de 2014}

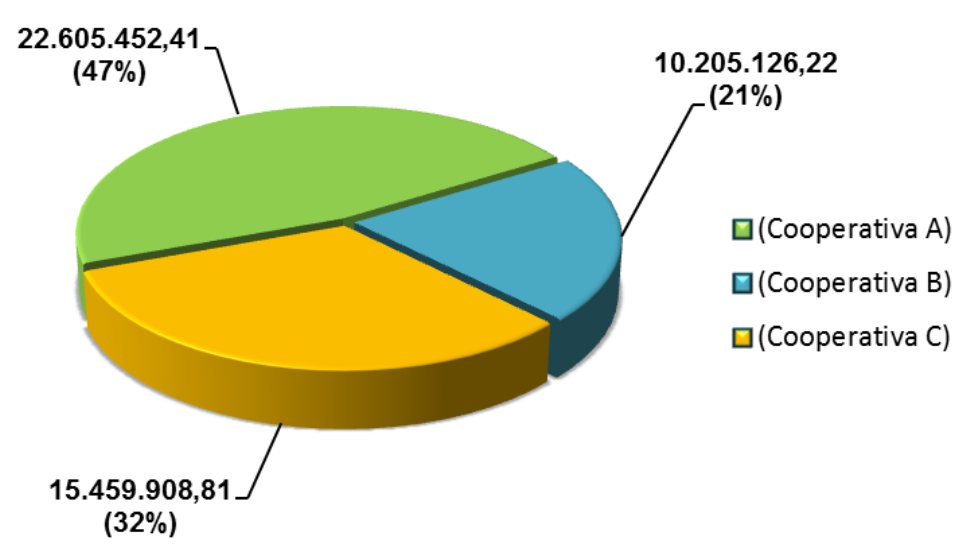

Figura 7: Carteiras de créditos das três cooperativas em 2014 (dados obtidos dos saldos das tabelas 1, 2, e3) 
Conclui-se que, para o exercício de 2014, a Cooperativa A permaneceu como a melhor gestora do risco de crédito, mesmo que seus percentuais de inadimplência para 15 e 90 dias tenham mais que dobrado, partindo de $0,42 \%$ e $0,23 \%$ para $1,11 \%$ e $0,57 \%$, nesta ordem. Nesta análise considerou-se como melhor gestora aquela que manteve os menores níveis de inadimplência em pontos percentuais no ano. Cabe ressaltar que a Cooperativa $\mathrm{B}$, manteve seus percentuais de inadimplência bem próximos aos níveis de 2013, e que a Cooperativa $\mathrm{C}$ obteve uma melhora significativa em seus percentuais de inadimplência de 15 e 90 dias, de $7,73 \%$ e $3,82 \%$ para $4,87 \%$ e $1,06 \%$, respectivamente. Nota-se que a gestão da cooperativa C, no período, foi a única que resultou em melhora na inadimplência, porém, os níveis continuam maiores do que os da cooperativa A.

Foi estruturado, por fim, o comparativo entre os percentuais de inadimplência de operações com atraso acima de 15 e 90 dias, para as Cooperativas A, B e C, referente ao ano de 2015, conforme Figura 8 a seguir.

Ao analisar a Figura 8, observa-se que no ano de 2015 a Cooperativa A permaneceu com os mais baixos índices de inadimplência para operações com atraso superior a 15 e 90 dias, superando, continuamente, as demais cooperativas. A Cooperativa B apresentou uma variação bastante significativa, ao alternar seus percentuais de inadimplência acima de 15 e 90 dias de, respectivamente, $3,95 \%$ e $1,5 \%$ em 2014, para $9,74 \%$ e $4,47 \%$. Quanto a Cooperativa C, obteve um aumento razoável no percentual de inadimplência de 90 dias, de 1,06\% em 2014, para 3,47\% em 2015, e o percentual de inadimplência acima de 15 dias apresentou uma irrisória melhora.

\section{Índice de inadimplência em 2015}

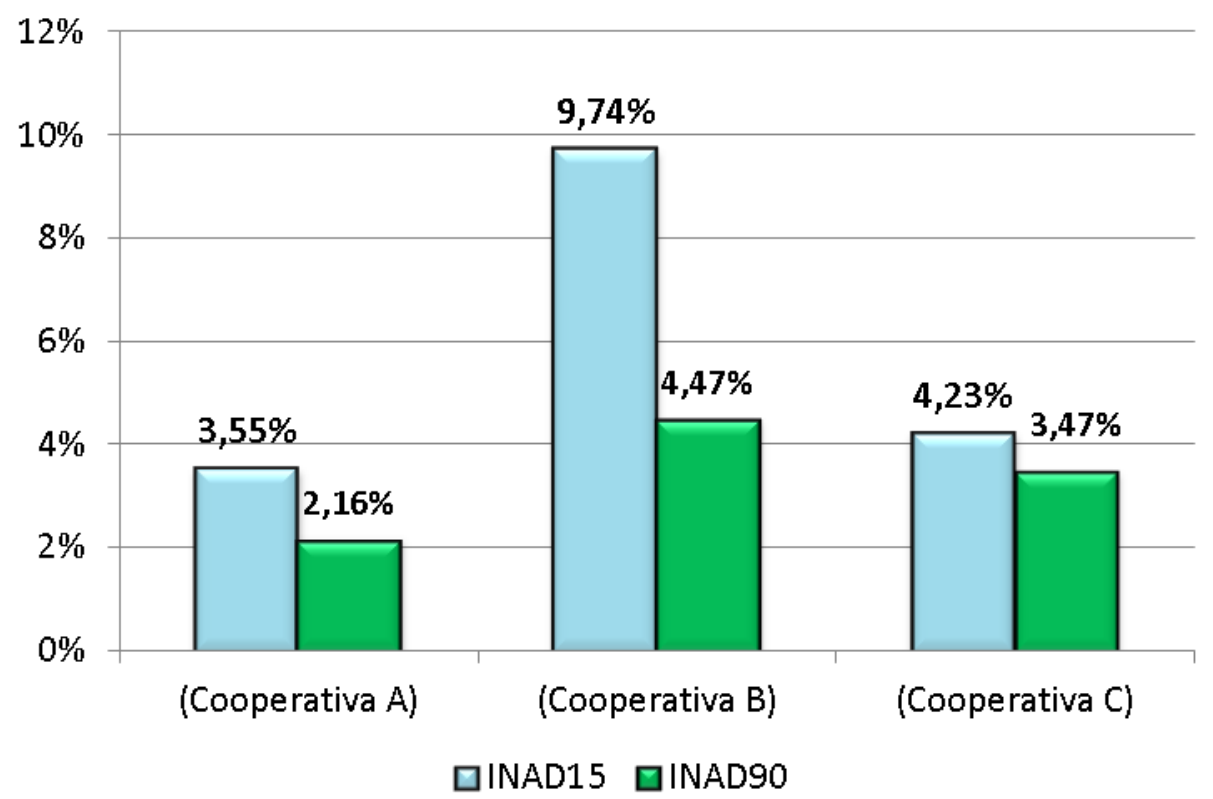

Figura 8: Comparativo da inadimplência de 15 e 90 dias em 2015

A seguir, a Figura 9, evidencia-se o conjunto das carteiras de crédito das três cooperativas e suas respectivas representatividades no ano de 2015. A Cooperativa A continua possuindo a maior carteira de crédito dentre as demais cooperativas, ocorrendo, porém, uma diminuição no saldo da Cooperativa C, e o saldo das Cooperativas A e B continua crescendo. 


\section{Carteiras de Crédito \\ Exercício de 2015}

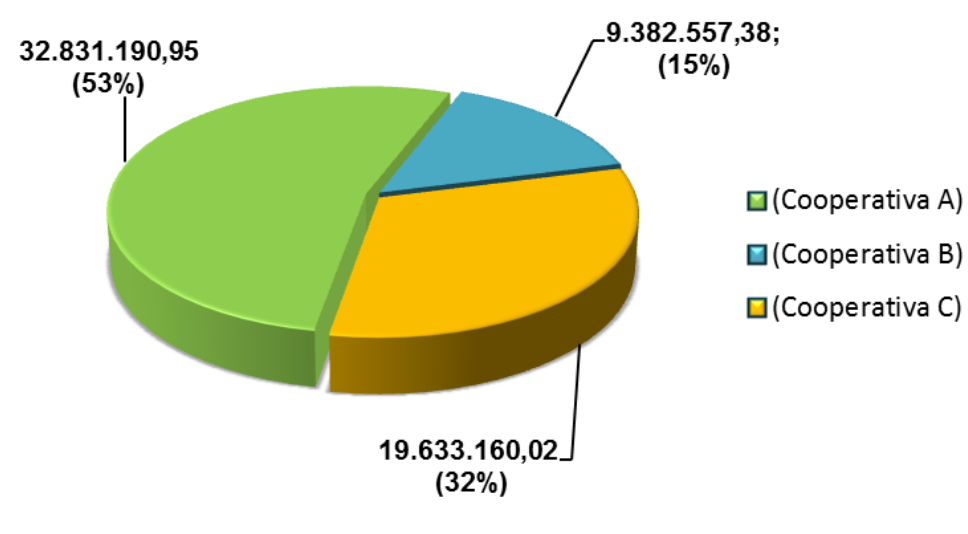

Figura 9: Carteiras de créditos das três cooperativas em 2015 (dados obtidos dos saldos das tabelas 1, 2, e3)

Perante os comparativos apresentados nas Figuras 4, 6 e 8, se finda que, delimitando-se aos períodos selecionados nesta pesquisa, a cooperativa de livre admissão (Cooperativa A) alcançou os mais baixos índices de inadimplência em todos os anos, resultados da melhor gestão de risco de crédito dentre as demais cooperativas.

Os índices de inadimplência acima de 15 e 90 dias da Cooperativa A alternaram, respectivamente, de $0,42 \%$ e $0,23 \%$ em 2013, para 3,55\% e 2,16\%, em 2015, conforme as Figuras 4 e 8. Julga-se este crescimento involuntário e indesejável, resultado do risco de crédito que se relaciona ao tipo da cooperativa, o de livre admissão, em conjunto com os impactos do abominável cenário econômico em que o Brasil transita, o qual potencialmente ocasiona desemprego, majora a inflação e diversos outros fatores pejorativos, que minimizam a capacidade de pagamento dos créditos tomados pelos cooperados.

Não menos importante, é possível evidenciar através desta pesquisa a única e significativa melhora dos percentuais de inadimplência que a cooperativa de microempresário (Cooperativa C) materializou, factível em função de sua gestão de risco de crédito. Conforme demonstrado nas Figuras 4 e 8, a Cooperativa $C$ reduziu seus percentuais de inadimplência acima de 15 e 90 dias de, respectivamente, $7,73 \%$ e 3,82\% em 2013, para 4,23\% e 3,47\% em 2015.

\section{CONCLUSÃO}

O estudo objetivou identificar qual dentre os tipos de cooperativa de crédito de livre admissão (Cooperativa A), profissionais (Cooperativa B) e micro empresários (Cooperativa C) logra a melhor gestão do risco de crédito, que resulta tacitamente nos mais baixos níveis de inadimplência, ou seja, esta pesquisa considerou como melhor gestora aquela que manteve os menores níveis de inadimplência em pontos percentuais nos anos de 2013, 2014 e 2015.

Evidencia-se que a cooperativa de livre admissão obteve uma gestão de risco de crédito mais eficaz nos três anos analisados, mantendo seus índices de inadimplência menores que os índices das cooperativas de profissionais e de microempresários, ainda que seus percentuais de inadimplência tenham se deteriorado no transitar dos períodos da pesquisa.

Vale enfatizar que somente as cooperativas de crédito que efetivamente gerenciam seus riscos de forma estratégica podem prever como sua carteira irá se comportar diante de um novo contexto 
macroeconômico, precificando devidamente suas operações, evitando exposições desnecessárias e habilitando-se a competir no mercado financeiro.

Ressalta-se, também, que o objetivo das cooperativas de crédito deve ser o gerenciamento e compensação do risco. Quando se empresta dinheiro existe a possibilidade de que o tomador não faça o pagamento no prazo estabelecido, porém as perspectivas de pagamento aumentam muito quando a cooperativa emprega instrumentos de avaliação de risco.

Este estudo indicou, ainda, que as cooperativas de crédito de livre admissão e de microempresários fomentaram sua atuação junto ao quadro de cooperados ao ampliarem o montante de suas carteiras de crédito. A carteira de operações de crédito da cooperativa de livre admissão cresceu, aproximadamente, $86 \%$ do ano de 2013 para o de 2015 e a carteira da cooperativa de crédito de microempresários cresceu, aproximadamente, $60 \%$ para o mesmo período.

Esta pesquisa está circunscrita a três cooperativas de crédito, sendo uma de cada tipo (livre admissão, profissionais e microempresários), e limitada ainda a uma análise horizontal de três anos (2013, 2014 e 2015), espera-se que outros estudos venham a acrescentar e suplementar o presente trabalho, com o intuito de agregar diversidade temporal e ou seletiva acerca do tema abordado.

Portanto, sugere-se que sejam realizados outros estudos ainda nessa área, da gestão do risco de crédito e do cooperativismo de crédito, quando que este último tem crescido em proporções cada vez maiores e de maneira muito rápida, ganhando espaço no Sistema Financeiro Nacional, como, por exemplo, fazer o mesmo estudo com cooperativas de crédito de outros tipos e que atuem em outro estado federado, ou um estudo que objetiva ratificar se o cooperativismo de crédito continua em processo de expansão mesmo em um cenário econômico desfavorável.

\section{REFERÊNCIAS BIBLIOGRÁFICAS}

1. Meinen E, Domingues JN, Domingues JAS (Org.). Cooperativas de crédito no Direito Brasileiro. Porto Alegre: Sagra Luzzatto; 2002. 112 p.

2. Vilares HC. O papel do cooperativismo financeiro na economia brasileira; 2014. Disponível em http://cooperativismodecredito.coop.br/2014/12/o-papel-do-cooperativismo-financeiro-na-economiabrasileira-por-henrique-castilhano-vilares/. Acessado em 16/03/2016.

3. Costa EG. Governança corporativa: conflitos de agência em cooperativas de crédito de Belo Horizonte. [Dissertação de Mestrado] - Faculdade Novos Horizontes, Belo Horizonte; 2015. 128 p.

4. Vilares HC. Cooperativas de crédito fortalecem a economia do país. Disponível em http://www.sicoobcrediembrapa.com.br/index.php/21-conteudo/noticias-sicoob/327-cooperativas-decrdito-fortalecem-economia-do-pas,-por-henrique-castilhano-vilares. Acessado em 16/03/2016.

5. Pagnussatt A. Guia do cooperativismo de crédito: organização, governança e políticas corporativas. Porto Alegre: Sagra Luzzatto; 2004.

6. Pinho DB, Palhares VMA (Org.). O cooperativismo de crédito no Brasil: do século XX ao século XXI. Brasília: Confebras; 2010. v. 2. 591 p.

7. Brasil, Congresso Nacional, Lei n. 4595 de 31 de dezembro de 1964. Dispõe sobre a Política e as Instituições Monetárias, Bancárias e Creditícias, Cria o Conselho Monetário Nacional e dá outras providências. Disponível em < http://www.planalto.gov.br/ccivil_03/Leis/L4595.htm>. Acessado em 16/03/2016

8. Tavares JFS. Gestão de riscos em cooperativas de crédito - caso SICREDI. Rev. FAE Business 2005 set.; 12: 28-30.

9. Brasil, Congresso Nacional, Lei n. 5764 de 16 de dezembro de 1971. Define a Política Nacional de Cooperativismo, institui o regime jurídico das sociedades cooperativas, e dá outras providências. Disponível em <http://www.planalto.gov.br/ccivil_03/Leis/L5764.htm>. Acessado em 16 mar. 2016.

10. Bacen. Relatório de inclusão financeira, n. 3 de 2015. Disponível em <https://www.bcb.gov.br/Nor/relincfin/RIF2015.pdf>. Acessado em 16/03/2016.

11. Bacen. Resolução 4.434 de 5 de agosto de 2015. Disponível em <http://www.bcb.gov.br/pre/normativos/busca/downloadNormativo.asp?arquivo=/Lists/Normativos/Att achments/48507/Res_4434_v2_L.pdf>. Acessado em 16/03/2016.

12. Bacen. Resolução 4.193 de 1 de março de 2013. Disponível em: <http://www.bcb.gov.br/pre/normativos/res/2013/pdf/res_4193_v2_P.pdf>. Acessado em 16/03/2016. 
13. Pinheiro FAP; Savóia JRF; Securato JR. Basiléia III: Impacto para os Bancos no Brasil. Revista de Contabilidade e Finanças 2015; 26(69): 345-361, doi: 10.1590/1808-057x201500720.

14. Jorion P. Value At Risk: a nova fonte de referência para o controle do risco de mercado. São Paulo: BM\&F; 1999.

15. Securato JR. Decisões financeiras em condições de risco. São Paulo; 1996.

16. Fernandes ENL. O impacto da informação contábil de empresas fechadas na percepção de risco dos analistas de crédito [dissertação]. São Paulo: Universidade de São Paulo; 2010. 111 p.

17. Saunders A. Financial institutions management: a modern perspective. Chicago: Irwin; 1997. 667 p.

18. Vergara SC. Projetos e Relatórios de Pesquisa em Administração. São Paulo: Atlas; 2009. 102 p.

19. Bacen. FAQ - Cooperativas de crédito; 2015. Disponível em http://www.bcb.gov.br/?COOPERATIVASFAQ. Acessado em 16/03/2016. 